\title{
Unveiling a Painpoint in a College Classroom: College Students' Perceptions of Academic Dishonesty and Some Tests of Correlations
}

\author{
Ruth Gutierrez*, Reynold Padagas \\ College of Liberal Arts, Criminology, and Education, Jose Rizal University, Philippines
}

Received October 17, 2019; Revised November 19, 2019; Accepted November 25, 2019

Copyright $\odot 2019$ by authors, all rights reserved. Authors agree that this article remains permanently open access under the terms of the Creative Commons Attribution License 4.0 International License

\begin{abstract}
In educational institutions, a culture of academic honesty is valued. However, while there is much awareness about the consequences of academic dishonesty, this is regarded as an endless academic concern. A sequential-explanatory mixed methods study assessed and explored the perceptions of 121 college students of a private Philippine university about academic dishonesty. Initially, a researcher-constructed questionnaire was administered to measure the perceptions of the respondents about academic dishonesty and correlated to their age, gender and course. A focus group discussion from seven purposively sampled respondents was conducted to extract deeper meanings of the survey results. The quantitative results disclosed that the college students have high perceptions about academic dishonesty. Meanwhile, age and gender were directly linked to academic dishonesty whereas the course did not associate with the college students' perceptions of academic dishonesty. Important information has been elicited and surfaced during the focus group discussions. This created complementarity of the quantitative and qualitative data and eventually resulted in a more profound, reflective analysis. School policy recommendations and interventions are suggested to enable the university to establish and sustain academic honesty as a culture within and among the members of the academic community especially its students, the end-receivers of good education.
\end{abstract}

\section{Keywords Perception, Academic Dishonesty,} Demographic Variables, College Classroom

\section{Introduction}

Most of the students know that cheating is an act of academic dishonesty. Despite the constant reminders of teachers and professors, students continuously do such even until they get caught. It appears as though the students do not understand what constitutes cheating and plagiarism (Lozier, 2012). A review of studies done on academic integrity shows an increase in academic dishonesty in higher education institutions. This increase has been attributed pressure from parents and peers, as well as the accessibility of the internet and technology advances.

Nowadays, technology disruptions have also caused tremendous concerns as this is considered as primary avenues where students can freely commit academic dishonesty. The accessibility of information online makes it very possible for students to just copy and paste information for their school requirements. Students become dependent on what the online platforms can readily provide them making them more lured to do many forms of academic dishonesty. Although there are dangers involved in doing such, most students believe that the benefits of cheating outweigh its risks (Niiya, Ballantyne, North \& Crocker, 2008).

Considerably, it is being argued that dishonest behavior does not begin upon entering college (Finn \& Frone, 2004). Research suggests that it typically starts in young people and increases by age but may not be necessarily associated with learning it at school or at home. It was also found out that men cheat more than women, especially those who are highly competitive and grade conscious. However, it can be noted that cheating, plagiarism and other mischievous academic acts are not directly linked to passing a course or a subject.

In this study, academic dishonesty is defined as wrongdoing or misbehavior practiced inside the classroom. This entails cheating and plagiarism. The primary focus of this study was to investigate the perceptions of college students about academic dishonesty. It is imperative to properly evaluate students' perceptions regarding academic dishonesty. Students' understanding of their acts 
is obtained to also revisit and discern about the effectiveness of the policies and guidelines of the institution regarding this issue. Likewise, playing the locus parentis role, teachers should be radical in finding ways to remedy such practice committed by students. Students should be aware of the consequences and implications of their actions, too. As stated in any educational institution's core values, students are developed to be responsible, considerate, courteous, and with integrity. These core values need to be articulated and lived by students at all times.

An important measure of the success of an academic institution is the evaluation of its moral health (Kasler, Hen \& Sharabi-Nov, 2019). There is a dire need to build a culture of academic honesty. It is essential to promote academic honesty and to strengthen regulations to control this important and relevant issue in the academic community. In order to do this, first and foremost, the policies and guidelines of the university should be clear and concise.

The researchers were prompted to conduct the study because dishonest behaviors such as cheating and plagiarism have become a grave problem among college students. The increasing number of students opting to cheat is very alarming. Since the youth is the future of our society towards positive change, the importance of academic integrity should be inculcated through strict implementation of school policies and regulatory mechanisms to eliminate academic dishonesty.

While the study is limited only to college students' perceptions about academic dishonesty, the researchers believe its importance to their own classrooms as well as to reach out to other institutions whose goal is to foster a culture of academic honesty at all levels.

\subsection{Background of the Study}

Academic dishonesty is not a new problem but it cannot be denied that various forms of academic dishonesty done either deliberate or not intended is a common concern in any educational institution. Thomas and Jeffers (2019) cited that academic dishonesty has been identified as a significant problem in tertiary educational institutions. However, even if it has been the subject of numerous studies offering explanations and recommendations, academic dishonesty persists (Cronan, Mullin, and Douglas, 2015). Several studies cited that academic dishonesty is normalized among college students (Krou, Acee, Pino \& Hoff, 2019; Baired, 1980; Swift \& Nonis, 1998).

Educational institutions such as colleges and universities are being compelled to establish a culture of academic honesty as this is essential in building an honest academic community that is committed and true to its vision and mission. As venues of values formation and sustenance, educational institutions are being challenged to overcome and resolved any dishonest behaviors among students. In this regard, the researchers conducted this study among selected college students in a private university in the Philippines. The goal was to know their perceptions about academic dishonesty and its relationships to their selected demographic profile variables such as gender, age, and course. The results of the study may be beneficial for the university to strengthen its implementation of the policies and guidelines on academic dishonesty.

The Deterrence Theory equates to the prevention of the occurrence of academic dishonesty among students. This theory proposed that cheating is a function of the severity of the consequences (DiPietro, 2010). Thus, if the academic institution wants to prevent or stop certain behavior such as cheating, the rules on punishment should be strengthened and strictly implemented. Previous studies show that minimal consequences are not enough punishment to discourage students to cheat. Likewise, instructors may opt to disregard going through the lengths of reporting the cheating behavior.

Substantially, Cochran (2015) found out that the effect of perceptual deterrence (i.e., the perceived likelihood of getting caught) on offending was dependent on an individuals' level of personal morality, such that the effect of perceptual deterrence was stronger for those individuals with lower levels of personal morality.

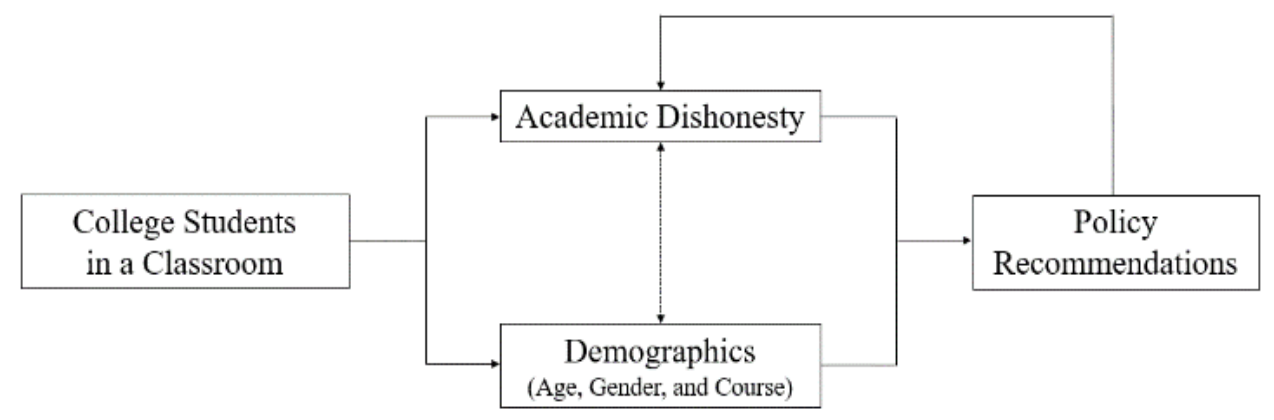

Figure 1. Conceptual Framework 
Figure 1 shows the conceptual framework of the study. The study investigates college students' perceptions about academic dishonesty and its relationships to their age, gender, and course. The findings are essential to the formulation of policy recommendations for the university.

\subsection{Research Questions}

This study focused on the following questions:

1. What were the college students' perceptions of academic dishonesty?

2. What were significant relationships exist between their perceptions of academic dishonesty and their selected demographics?

\subsection{Research Hypothesis}

The following hypotheses were tested using $\alpha$ of .05 alpha level of significance:

$\mathrm{H}_{01}$ Age does not correlate significantly to the college students' perceptions of academic dishonesty.

$\mathrm{H}_{02}$ Gender does not correlate significantly to the college students' perceptions of academic dishonesty.

$\mathrm{H}_{03}$ Course does not correlate significantly to the college students' perceptions of academic dishonesty.

\section{Materials and Methods}

\subsection{Research Design}

Mixed methods research involves the use of qualitative and quantitative data in a single research project. It represents an alternative methodological approach, combining qualitative and quantitative research approaches, which enable nurse researchers to explore complex phenomena in detail (Halcomb \& Hickman, 2015).

A sequential-explanatory mixed methods design was used in this study. In sequential-explanatory mixed methods research, there are two phases of data gathering and these include 1.) quantitative phase and 2.) qualitative phase. Through this design, the researchers uncovered salient findings using a complementary blend of results from the quantitative and qualitative data analyses.

\subsection{Research Sample}

College students enrolled during the school year 2015-2016 were the target respondents for this study. Convenience sampling was used to easily obtain more respondents who were willing to participate. A total of 121 college students were asked to answer the survey questionnaire on-line. Out of these 121 college students, there were 54 females and 67 males. Of the total number of respondents, 76 students graduated high school from private institutions and 44 from public institutions.
Regarding their age distribution, $76.86 \%$ belonged to $16-21$ age, while $18.18 \%$ belonged to $22-25$ and the remaining $4.96 \%$ belonged to 26 years old and above. The said respondents were composed of 37 students taking Bachelor of Science in Information Technology (BSIT), 25 students taking Bachelor of Science in Accountancy (BSA), 12 students taking Bachelor of Science in Business Administration (BSBA), 6 students taking Bachelor in Secondary Education (BSEd), 5 students taking Bachelor of Arts in English (AB English), 5 students taking Bachelor of Arts in Psychology (AB Psychology) and the remaining 27 students did not mention their specific programs.

Their responses were downloaded and converted to excel from Google form. Meanwhile, in the FGD, there were seven (7) participants, three (3) females, and four (4) males. They were the students who submitted themselves to participate as FGD key informants. The researchers decided that the FGD shall be facilitated by a trained student leader to elicit more honest responses from the respondents. The responses in Filipino were translated by the researchers into English since they speak and understand the language. The transcripts and translations were given back to the key informants to be able to validate and clarify contents and meanings.

\subsection{Research Instrument}

During the initial phase of this study, a survey questionnaire was made by the researchers to gather quantitative data regarding the college students' perceptions about academic dishonesty with emphasis on cheating and plagiarism. A 5-point rating scale was utilized in the said questionnaire with a specific description of each scale. The questionnaire was pilot-tested and yielded a .82 Cronbach alpha result. A Cronbach alpha of more than .60 means that the items in the questionnaire are all internally consistent hence can provide reliable results.

Meanwhile, FGD was the primary data gathering technique employed in the qualitative part of this research. The FGD protocol was designed and comprised of questions rooted in the problem statement of this study. Since the study focused on college students' perceptions of academic dishonesty, exploratory questions were asked. The respondents are composed of seven (7) volunteered participants range 16-30 years old. The FGD was employed to deepen the understanding of the phenomenon to be explored.

\subsection{Treatment of Data}

For the quantitative data, descriptive statistics were employed such as mean scores, and weighted means. To determine the relationship between the perceptions of the college students on academic dishonesty and their selected demographics such as age, gender, and course, a Chi-square test was utilized. 
However, for the qualitative data obtained from the FGDs, content analysis was conducted as data treatment. The content analysis generated themes. The results of the content analysis were used to understand the phenomenon explored in this study.

The quantitative and qualitative results were then integrated and both equally and substantially explained academic dishonesty from the lens of the college students.

\subsection{Ethical Considerations}

Ethical considerations were duly considered in conducting this study. The study went through an institutional ethics review. Pertinent documents were evaluated prior to the actual data collection. Individual informed consent was obtained from the college students as respondents of this study. Anonymity and confidentiality of personal information gathered from them were secured.

The researchers treated the data with treatment measures and analyses free from any biases or prejudices.

\section{Results and Discussions}

To answer the research questions stated in the statement of the problem, Tables 1 to 4 exhibit the findings with essential analyses and interpretations.

Table 1. Mean Distribution of the College Students' Perceptions of Academic Dishonesty

\begin{tabular}{|l|c|c|}
\hline \multicolumn{1}{|c|}{ Perceptions } & MS & Interpretation \\
\hline $\begin{array}{l}\text { If I cheat, I would lose my } \\
\text { self-respect. }\end{array}$ & 3.98 & High \\
\hline I am afraid of being caught cheating. & 4.30 & High \\
\hline $\begin{array}{l}\text { I do not want to give in to group } \\
\text { pressure to do things that I do not } \\
\text { believe in. }\end{array}$ & 4.21 & High \\
\hline $\begin{array}{l}\text { I consider it my honor to uphold } \\
\text { academic integrity. }\end{array}$ & 4.60 & Very high \\
\hline $\begin{array}{l}\text { I am confident that I know what my } \\
\text { school's academic honesty policy } \\
\text { says. }\end{array}$ & 4.10 & High \\
\hline $\begin{array}{l}\text { I usually get a better score if I cheat. } \\
\text { It is easy to use the internet to cheat } \\
\text { on assignments or tests in college. }\end{array}$ & 2.80 & High \\
\hline $\begin{array}{l}\text { Students cheat on assignments or } \\
\text { tests at least once in a while in } \\
\text { college. }\end{array}$ & 3.40 & Average \\
\hline $\begin{array}{l}\text { Using the internet to cheat makes it } \\
\text { more difficult to get caught by } \\
\text { instructors. }\end{array}$ & 2.80 & Average \\
\hline \begin{tabular}{l} 
High \\
\hline
\end{tabular} & 3.75 & Avean \\
\hline
\end{tabular}

Generally, it can be gleaned from Table 1 that the college students have high perceptions about academic dishonesty. Likewise, overall, the outcome of the focus group discussion on the respondent's perception and opinion on cheating and plagiarism provides a lot of lessons to reflect on. The respondents think that cheating and plagiarism are both dishonest acts. Some of them believed that it's a normal part of life as a student. It also saves time and effort in answering the examinations.

On the other hand, one student mentioned: "When you cheat, you are not only fooling your professor but also yourself. In the end, you learn nothing." (Student D, Female, 21 years old)

Some students get to have considered cheating as a way of life although cheating is regarded as a bad act.

Majority of the participants in the focus group discussion were aware that cheating and plagiarism are a crime. They even revealed that a lot of students are doing this and it's the practice of students during the exam. Plagiarism for them is using others' work without crediting the author.

The understanding of the students about cheating and plagiarism is somewhat clear that it is an act of fraud. Furthermore, it is something that they cannot avoid because it occurs inside the classroom. They understand that cheating is an act of fraud while plagiarism is copying the entire work of another person.

Students' awareness with regard to forms of cheating and plagiarism is prevalent. Through the use of hands, pen and paper and taking pictures, cheating and plagiarism are made. The worse is copying the entire answer of the assignment from internet sites like Google. The majority of the participants in the focus group discussion admitted that they submitted a paper that is copied. Although one of them said it was done unintentionally without citing the source and another said it was partially done.

The students have considered their honor to uphold academic integrity as reflected in item no. 4.

This is supported by one participant during the FGD when she said:

"I always make sure that I do not cheat during examinations or tests, especially in our online or blended courses. I trust my capacity that I can answer the questions in the tests since I always review and listen to my teachers during lectures. Honesty during examination is best exemplified when I do exactly what I have to do without cheating just to pass my examinations." (Student A, Female, 19 years old)

A high level of self-control is necessary to be able to prevent one's self from cheating. Blachnio (2019) found out that academic dishonesty and self - control were negatively related to academic cheating. This means that when students have low self-control, they tend to commit academic honesty.

One student participant also highlighted that "...it is serious to commit cheating and plagiarism." (Student D, Female, 21 years old)

This statement that surfaced during the FGD supports the study of Kasler, He, and Sharabi-Nov (2019) when they found out that students perceived academic misconduct as a serious matter. Academic dishonesty necessitates control and discipline. A preventive measure on such is imperative, especially for vulnerable students. 
It can be noted that in this study, the students have a fear of cheating as reflected in item no. 2. However, it can be determined that they have a notion that when they cheat, they can get high scores as identified in item number 6 . These findings are supported by the following responses during the FGD.

"I am afraid to cheat but I do it because I want to pass." (Student G, Male, 20 years old)

"I am fearful to cheat but when I have the chance I have to do it because I have to pass my subject." (Student B, Female, 19 years old)

"I know I can get better scores in my quizzes when I cheat." (Student C, Male, 18 years old)

Based on class observations with regard to the academic standing of the students, the researchers can nullify the idea that cheating can increase academic performance as perceived by the students. Indeed, there is no link between passing a test and cheating especially when the teachers employ strict monitoring during tests and examinations or any other learning-related activities.

Good classroom management can prevent any forms of academic dishonesty in the class. Without a doubt, when the teacher sets guidelines on academic honesty as a culture in the class, the students will be reoriented about the consequences academic dishonesty can create. Classroom management entails the capacity of the teacher to impose discipline among students. Considering the expected desired skill of the teachers in employing such, desired learning objectives can be achieved at its best while attaining values formation in students, something that is identified as an implied curriculum essential in honing a holistic learner.

This is supported by one participant saying:

"If the teacher is strict, maybe I will not cheat." (Student D, Male, 19 years old)

no other participant also mentioned that:

"If the teacher is a disciplinarian, I guard my behavior." (Student E, Male, 21 years old)

"My teacher uses dark glasses when we have examinations. I have no chance to cheat because I am not sure if she is looking at me." (Student F, Male 23 years old)

Several interventions can be made to be able to minimize if not to eliminate academic dishonesty in the classroom. Clark and Soutter (2016), as cited by Krou Acee, Pino \& Hoff (2019) argued for a broad character education approach addressing cheating culture both at the class and school levels.

In a classroom, the teachers can come up with measures to be able to prevent academic dishonesty. The researchers, for instance, conduct regular lectures in using platforms such as Turnitin and Unicheck to reorient the students the importance of honesty and integrity in the academic world. Being familiar with these platforms and that they are made readily available for them limits the risks of students in committing plagiarism.
These findings complement the response of one of the participants during the FGD. He said:

"My teacher used to give us reports about plagiarism when we submit our theses chapters to him." (Student A, Female, 19 years old)

At a school level, it is essential that the school administration must have well-defined, clear-cut rules about academic dishonesty. It is not enough that punishments be emphasized to be able to control students in doing cheating, plagiarism or any other mischievous behaviors. There is a need for information and awareness drive to deliver the message on the call to live academic honesty at all times. Values reformation must be well-established so as to help students and those at the highest risks to commit academic dishonesty to be guarded.

"I know that dishonesty is clearly a major offense in the university but I think (I am not sure enough) if punishments like expulsion or suspension are given to the offenders. I am not really sure." (Student A, Female, 19 years old)

Table 2. Chi-Square Test Results for the Relationship Between their Perceptions of Academic Dishonesty and their Age

\begin{tabular}{|l|c|c|c|}
\hline \multicolumn{1}{|c|}{ Items } & Value & df & $\begin{array}{c}\text { Asymptotic } \\
\text { significance } \\
\text { (2-sided) }\end{array}$ \\
\hline $\begin{array}{l}\text { If I cheat I would lose my } \\
\text { self-respect }\end{array}$ & 10.78 & 12 & .548 \\
\hline $\begin{array}{l}\text { I am afraid of being caught a } \\
\text { cheating }\end{array}$ & 5.859 & 12 & .923 \\
\hline $\begin{array}{l}\text { I do not want to give in to group } \\
\text { pressure to do things that I do } \\
\text { not believe in. }\end{array}$ & 2.530 & 12 & .998 \\
\hline $\begin{array}{l}\text { I consider it my honor to uphold } \\
\text { academic integrity. }\end{array}$ & 8.763 & 12 & .723 \\
\hline $\begin{array}{l}\text { I am confident that I know what } \\
\text { my school's academic honesty } \\
\text { policy says. }\end{array}$ & 6.756 & 12 & .873 \\
\hline $\begin{array}{l}\text { I usually get a better score if I } \\
\text { cheat. }\end{array}$ & 128.1 & 16 & .000 \\
\hline $\begin{array}{l}\text { It is easy to use the Internet to } \\
\text { cheat on assignments or tests in } \\
\text { college. }\end{array}$ & 130.7 & 20 & .000 \\
\hline $\begin{array}{l}\text { Students cheat on assignments or } \\
\text { tests at least once in a while in } \\
\text { college. }\end{array}$ & 132.3 & 20 & .000 \\
\hline $\begin{array}{l}\text { Using the Internet to cheat makes } \\
\text { it more difficult to get caught by } \\
\text { instructors. }\end{array}$ & 129 & 20 & .000 \\
\hline
\end{tabular}

To understand the correlations between the perceptions of the college students about academic honesty, Table 2 shows that item numbers 1 to 5 are not significantly correlated to the age of the respondents. On the other hand, the rest of the items are found to be of high correlations to the age of the respondents.

When asked if they think age matters in committing acts of academic dishonesty, some participants mentioned the following:

"I think as one gets older, the greater the chance of cheating." (Student D, Male, 19 years old)

"Younger students do not cling on cheating that much. 
Maybe because they are afraid of their teachers." (Student E, Male, 21 years old)

"I have a classmate who is already mature like 30 years old and is still cheating. He used to do it may be because he has no time in studying anymore as he is so busy with his work." (Student A, Female, 19 years old)

"I don't think so. Everyone, when given the opportunity to cheat, will cheat." (Student A, Female, 19 years old)

Their responses to the question rose during the FGD show that the college student participants are differentiated in their understanding of whether or not age has a link to doing academic dishonesty.

Straw (2002) found out that first year and second-year undergraduates were more likely to perform academic dishonesty acts compared to third-year and fourth-year undergraduates. In 2003, Pino \& Smith discovered that older college students have a higher affinity or propensity to cheat.

Table 3. Chi-Square Tests Results for the Relationship Between their Perceptions of Academic Dishonesty and their Gender

\begin{tabular}{|l|l|l|c|}
\hline \multicolumn{1}{|c|}{ Items } & Value & df & $\begin{array}{c}\text { Asymptotic } \\
\text { significance } \\
\text { (2-sided) }\end{array}$ \\
\hline $\begin{array}{l}\text { If I cheat I would lose my } \\
\text { self-respect }\end{array}$ & 4.024 & 4 & .403 \\
\hline $\begin{array}{l}\text { I am afraid of being caught a } \\
\text { cheating }\end{array}$ & 15.50 & 4 & .004 \\
\hline $\begin{array}{l}\text { I do not want to give in to group } \\
\text { pressure to do things that I do } \\
\text { not believe in. }\end{array}$ & 2.020 & 4 & .732 \\
\hline $\begin{array}{l}\text { I consider it my honor to uphold } \\
\text { academic integrity. }\end{array}$ & 2.980 & 4 & .570 \\
\hline $\begin{array}{l}\text { I am confident that I know what } \\
\text { my school's academic honesty } \\
\text { policy says }\end{array}$ & 6.515 & 4 & .164 \\
\hline $\begin{array}{l}\text { I usually get a better score if I } \\
\text { cheat. }\end{array}$ & 129.5 & 8 & .000 \\
\hline $\begin{array}{l}\text { It is easy to use the Internet to } \\
\text { cheat on assignments or tests in } \\
\text { college }\end{array}$ & 124.9 & 10 & .000 \\
\hline $\begin{array}{l}\text { Students cheat on assignments or } \\
\text { tests at least once in a while in } \\
\text { college. }\end{array}$ & 123.0 & 10 & .000 \\
\hline $\begin{array}{l}\text { Using the Internet to cheat makes } \\
\text { it more difficult to get caught by } \\
\text { instructors. }\end{array}$ & 128.3 & 10 & .000 \\
\hline
\end{tabular}

Table 3 shows the relationships between the items on perceptions and the gender of the respondents. The findings posit that gender has no significant link to the perceptions of students about academic honesty. The results of this study contradicted the findings of Blachnio (2019) when she found out that women scored lower than men on academic dishonesty. It was also reported that men self-reported more cheating behavior like test cheating, plagiarism, and false excuses compared to women (Hensley, Kirpatrick, \& Burgoon, 2013), as cited in the study of Blachnio (2019).

When asked about the relationship of gender to academic dishonesty like cheating and plagiarism, some participants cited the following:

"I think men cheat more than women in so many ways." (Student E, Male, 21 years old)

"Male and female students equally cheat especially when they are friends. Cheating happens and it is uncontrollable." (Student E, Male, 21 years old)

"Women cheat less frequently than men." (Student F, Male 23 years old)

"It is unfair when people say that men cheat more than women. It looks like "all" men are bad. It is not true." (Student D, Male, 19 years old)

The respondents' responses to the question also vary. There is a marked disparity in the way they responded. It can be understood that cheating happens regardless of gender. Engendering academic honesty is biased. Academic dishonesty is affected by more comprehensive and specific factors other than gender.

Table 4. Chi-Square Tests Results for the Relationship Between their Perceptions of Academic Dishonesty and their Course

\begin{tabular}{|l|c|c|c|}
\hline \multicolumn{1}{|c|}{ Items } & Value & Df & $\begin{array}{c}\text { Asymptotic } \\
\text { significance } \\
\text { (2-sided) }\end{array}$ \\
\hline $\begin{array}{l}\text { If I cheat I would lose my } \\
\text { self-respect }\end{array}$ & 113.3 & 112 & .448 \\
\hline $\begin{array}{l}\text { I am afraid of being caught a } \\
\text { cheating }\end{array}$ & 159.7 & 112 & .002 \\
\hline $\begin{array}{l}\text { I do not want to give in to } \\
\text { group pressure to do things } \\
\text { that I do not believe in. }\end{array}$ & 95.5 & 112 & .897 \\
\hline $\begin{array}{l}\text { I consider it my honor to } \\
\text { uphold academic integrity. }\end{array}$ & 69.76 & 112 & .999 \\
\hline $\begin{array}{l}\text { I am confident that I know } \\
\text { what my school's academic } \\
\text { honesty policy says }\end{array}$ & 116.8 & 112 & .358 \\
\hline $\begin{array}{l}\text { I usually get a better score if } \\
\text { I cheat. }\end{array}$ & 75.01 & 112 & 140 \\
\hline $\begin{array}{l}\text { It is easy to use the Internet to } \\
\text { cheat on assignments or tests } \\
\text { in college }\end{array}$ & 123.7 & 140 & .997 \\
\hline $\begin{array}{l}\text { Students cheat on } \\
\text { assignments or tests at least } \\
\text { once in a while in college. }\end{array}$ & 117.6 & 140 & .835 \\
\hline $\begin{array}{l}\text { Using the Internet to cheat } \\
\text { makes it more difficult to get } \\
\text { caught by instructors. }\end{array}$ & 137.8 & 140 \\
\hline
\end{tabular}

Table 4 presents the relationship between college students' perception of academic dishonesty and their course. Only item number 2 is significantly correlated to the students' perception of academic dishonesty.

When asked about the relationship between academic dishonesty and course, the students responded differently.

"Maybe those who are in the more difficult courses like engineering or information technology." (Student D, Male, 19 years old)

"I cannot tell any course because, for me, everyone does it. No such thing like more on this course or that course." (Student E, Male, 21 years old)

One study ascertained that students majoring in science, technology, engineering, math, or business performed the 
majority of cheating behaviors on campuses (Williams, Nathanson \& Paulhus, 2010). It can be noted that there is a dearth of studies on this matter and like gender. The results could be somehow affected by various factors.

\section{Conclusions}

Academic dishonesty exists in many forms such as cheating, plagiarism, falsifying various reasons to escape from responsibilities among other things. This might be done intentionally or unintentionally. In this study, while college students have high perceptions about academic dishonesty, some students still tend to commit such acts as marring their academic integrity. The commission of these mischievous activities may be affected by several factors such as intrapersonal and external factors. Intrapersonal factors comprise the innate motivations of students to commit academic dishonesty whereas the external factors are associated with teachers, schools, families, peers or friends, among others.

There is no single measure to prevent resolve academic dishonesty in college students based on literature but the teachers and the schools play very crucial roles to help students live with academic integrity. The teachers need to help students be reminded of the value of academic honesty as an essential tool to succeed in higher learning. And, as venues of values formation, the schools must create venues where students can demonstrate their full knowledge, skills, and attitudes towards building a culture of academic honesty.

In this study, some school policy recommendations could be pursued to prevent academic dishonesty among college students. It is recommended that student manual should be reviewed and revised so that all information is up to date. Distribution of the said manual or maybe via the website must be done to all students to easily disseminate information regarding the university's policy and guidelines. Classroom orientation with regard to university policies and guidelines should always be practiced by the teachers. Moreover, the teachers must strictly implement the policies and guidelines of the university and emphasize the consequences of violations that will be committed. Habitual violators should undergo guidance and counseling for behavioral management. Further studies on the same using different methods of research are also hereby suggested.

\section{Acknowledgements}

The researchers extend their warmest regards to Dr. Vicente K. Fabella, Dr. Miguel M. Carpio, Dr. Barbara Wong-Fernandez, Dr. Auxencia C. Limjap, Dr. Henry C. Magat and Dr. Teresita C. Dijamco for their endless support. This is a G-Res project under the Research Office of Jose Rizal University, Philippines.

\section{REFERENCES}

[1] A. Katie A. Lozier, Student Paper of Academic Dishonesty Scenarios, 2012. Retrieved from http://cardinalscholar. bsu.edu/bitstream/handle/123456789/195858/Student $\% 20$ Perceptions\%20of\%20Academic\%20Dishonesty\%20Scena rios.pdf? sequence $=1 \&$ isAllowed $=\mathrm{y}$.

[2] Y. Niiya, R. Ballantyne, M.S. North, \& J. Crocker, Gender, contingencies of self-worth, and achievement goals as predictors of academic cheating in a controlled laboratory setting. Basic and Applied Social Psychology, 30(1), 76-83, 2008, Retrieved from http://dx.doi.org/10.1080/019735307 01866656.

[3] K.V. Finn and M.R. Frone, Academic Performance and Cheating: Moderating School Identification and Self-Efficacy, The Journal of Educational Research, 97(3): 115-121, January 2004.

[4] J. Kasler, M. Hen, \& A. Sharabi-Nov, Academic Integrity in Higher Education: the Case of a Medium-Size College in the Galilee, Israel. Journal of Academic Ethics, 17(2), 151-167, 2019.

[5] J. Thomas, \& A. Jeffers, Mobile eye-tracking and academic integrity: A proof-of-concept study in the United Arab Emirates. Accountability in research, 1-9, 2019.

[6] T.P. Cronan, J.K. Mullins, \& D.E. Douglas, Further understanding factors that explain freshman business students' academic integrity intention and behavior: Plagiarism and sharing homework. Journal of Business Ethics, 147(1), 197-220, 2018.

[7] M.R. Krou, T.W. Acee, N.W. Pino, \& M.A. Hoff, Rationalizing the Decision to Cheat: An Empirical Analysis to Determine Whether Social Rational Orientation Can Predict Academic Dishonesty. Journal of College and Character, 20(1), 9-24, 2019.

[8] J. Baird, Current trends in college cheating. Psychology in the Schools, 17, 515-522, 1980 DOI: 10.1002/(ISSN)1520 -6807 .

[9] C. Swift, \& S. Nonis, When no one is watching: Cheating behaviors on projects and assignments. Marketing Education Review, 8(1), 27-36, 1998.

[10] M. DiPietro, Theoretical frameworks for academic dishonesty. In: Nilson LB, Miller JE. To Improve the Academy, Vol. 28, 2010/

[11] E. Halcomb, \& L. Hickman, Mixed methods research. Nursing Standard: promoting excellence in nursing care, 29 (32), 41-47, 2015.

[12] A. Błachnio, Don't cheat, be happy. Self-control, self-beliefs, and satisfaction with life in academic honesty: A cross-sectional study in Poland. Scandinavian journal of psychology, 60(3), 261-266, 2019.

[13] S.S. Clark, \& M. Soutter, A broad character education approach for addressing America's cheating culture. Journal of Character Education, 12(2), 29-42, 2016.

[14] D. Straw, The plagiarism of generation 'why not?' 
Community College Week, 14(24), 4-7, 2002.

[15] N. Pino, \& W. Smith, African American students, the academic ethic, and GPA. Journal of Black Studies, 35(1), 113-131, 2004 DOI:10.1177/0021934704264954San 